\title{
Teacher Cognition vis-à-vis Vocabulary Teaching
}

\author{
Siamak Rahimi \\ Shahid Beheshti University, Tehran, Iran
}

\begin{abstract}
What teachers know, believe, and discover about all aspects of their work during the classroom processes have been firmly requested since 1990s as a comprehensive investigation. In addition, vocabulary and the process of its construction according to a specific psycholinguistic model and the procedure of learning is a corresponding familiar topic in relation to teacher cognition. This paper is a case study considering four experienced teachers to recognize whether the process and constant syllabus of teaching vocabulary is interconnected to the materials or to the teacher's prior experience knowledge, beliefs, and culture. Consequently, such research is conducted to verify the assumption of vocabulary teaching as the teachers perceive it, and the influential information which can be practical in teacher education and development programs as well.
\end{abstract}

Index Terms - teacher cognition, vocabulary learning, prior knowledge, psycholinguistic model

\section{INTRODUCTION}

The integral assumption of this paper can be condensed according to the research on second language pedagogy. To elucidate the preceding conceptualization, and consider all the related underpinning aspects of teacher cognition, the following criteria are established:

1. Teaching vocabulary and the related activities to enhance learning vocabulary has been one of the heated discussions for quite a long time, and describing a psycholinguistic model in relation to teachers' perceptions, beliefs, and knowledge is a state-of-the-art research.

2. "How teaching and learning takes place in context is the main goal of classroom research" (Dornyei, 2007). Teacher's decisions and thinking are powerfully affected by their cognitions about teaching and learning (Borg, 1999). In addition, action research is done by teachers in order to achieve a better understanding of their pedagogical procedure and improving the effectiveness of their teaching (Dornyei, 2007). This research is utilized to observe the growth of reflective skills in teachers in the classroom through the action research.

The aim of this paper is the study of vocabulary teaching and teacher cognition by expanding on each with reference to the literature on both topics. The current process demonstrates teachers' understandings about vocabulary teaching and learning through classroom observations and the comparison with teachers' prior knowledge, education, and experience.

The relationship of teacher cognition and vocabulary teaching is a relatively unexplored topic, but the study of teacher cognition, in relation to other skills has been surveyed quite a lot. Borg (2003) describes 1990-2000 as the "decade of change", and also he identified 64 studies published between 1976 and 2002 in research on teacher knowledge and learning to teach, but the host of research on teacher cognition initiated in the 1990s.

In terms of topics and contexts, two integral areas in second language teaching have been scrutinized. As Borg (2003) puts it, 22 studies about grammar and 5 studies about reading in relation to teacher cognition is conducted up to the present time.

\section{A. Teacher Cognition}

Teacher cognition is defined as teacher's mental lives. Broadly speaking, it examines what teachers in second and foreign language contexts think, believe, or assume in relation to different aspects of their professions. Teacher cognition is a multidimensional conceptualization of teaching which encompasses schooling; early prolonged experience during initial learning, professional coursework; about syllabi, subject matter, practices and etc, contextual factors and classroom practice. This multidimensional term is better clarified according to Fig. 1, representing different aspects of teacher cognition by Borg (1997): 

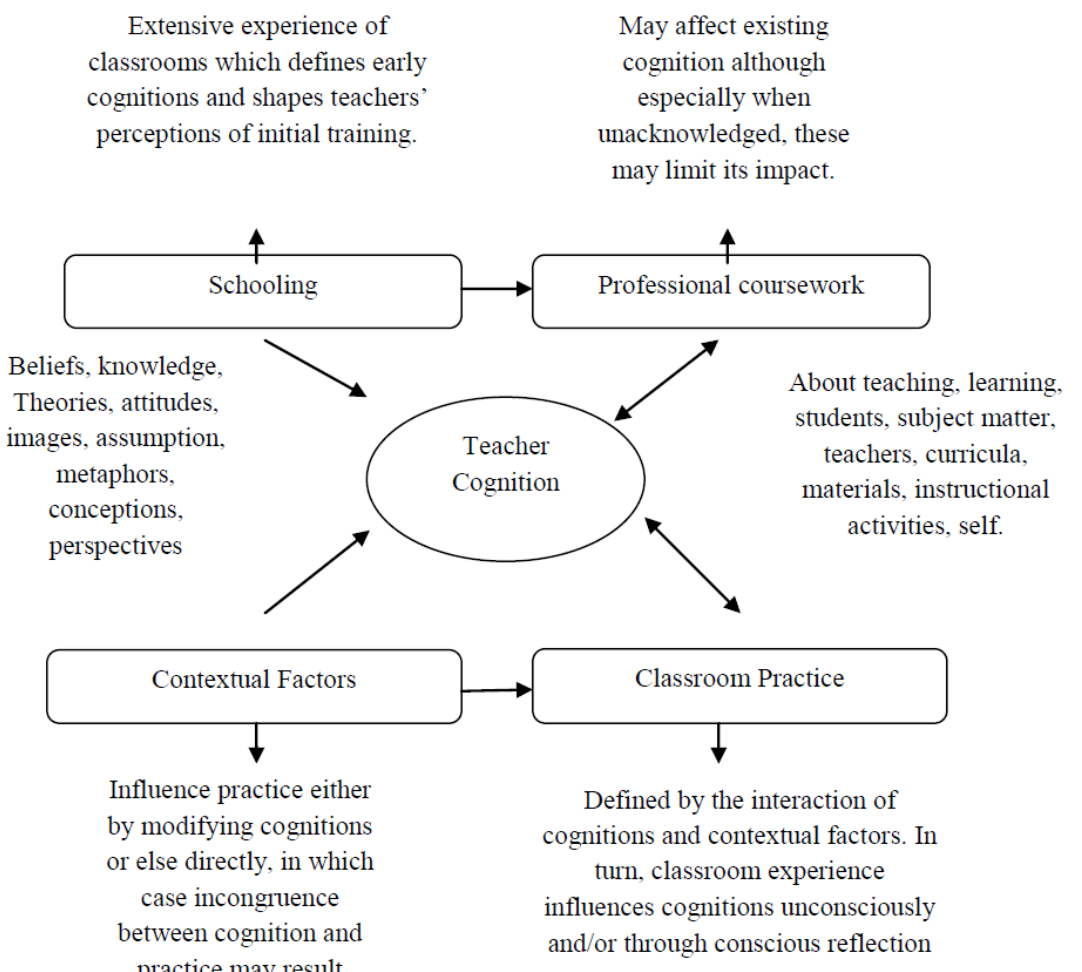

Figure 1. Teacher cognition, schooling, professional education, and classroom practice (Borg, 1997)

In order to elaborate more on the procedure of teacher cognition in decision making during teaching vocabulary, a three-model theme adapted from Borg (2003) is considered: 1) cognition and prior language learning experience 2) cognition and teacher education, and 3) cognition and classroom practice.

The first theme involves the huge amount of experience that teachers accumulate during their experience as learners, what (Lortie, 1975) coined their 'apprenticeship of observation'. The vast numbers of research has been conducted about teachers' prior knowledge in relation to their work. (e.g., Bailey et al. 1996; Farrel 1999; Freeman 1993; Golombek 1998; Johnson 1994; Richards \& Pinnigton 1998).

The second theme deals with the impact of teacher education and cognitive change. Lots of criticisms rejected the relationship as significant e.g. (Kagan, 1992), but a host of research believed in change of cognition in accordance with variable outcomes and individual developmental pathways (Freeman, 1993; Richards, Ho \& Giblin, 1996).

In addition to the process of growth and self-development through pre-service and in-service education, the amalgamation of knowledge is not constrained to the previous knowledge, but to the ongoing process of classroom practices. During these practices, numerous considerations worth taking into account such as pedagogical concerns and knowledge, instructional considerations and maxims (Bailey, 1996; Bartels, 1999; Richards, 1996).

\section{B. Vocabulary Teaching}

Second language acquisition theory considers syntax, a pivotal part, while, vocabulary acquisition and lexical development, as (Mitchell \& Myles, 1998) puts it, is treated in a "semi-autonomous way". Broadly speaking, most of the effective SLA models are tending toward comprehension, interaction, or production, as noted in (Cumming, 1990). To summarize, there has been a gap between syntax and lexical processing and development and in order to bridge the gap and also find a balanced view toward vocabulary acquisition, model builders should try to approach it as an integrating component into other frameworks not as ancillary, or "on the side" as it were (Haastrup and Henriksen, 2001).

In view of the fact, teachers' retrospective rationalization of what they do unconsciously during the classroom procedures is dependent upon teachers' mental lives, considering a psycholinguistic model in relation to vocabulary acquisition is indispensable. Fig. 2, presented by (Haastrup and Henriksen, 2001), considers all related dimensions of an appropriate psycholinguistic model to vocabulary learning. This model takes anthology of vocabulary research into consideration according to (Coady and Huckin, 1997) (Harley, 1995) (Paribakht and Wesche, 1999) (Schmitt and McCarthy, 1997): 


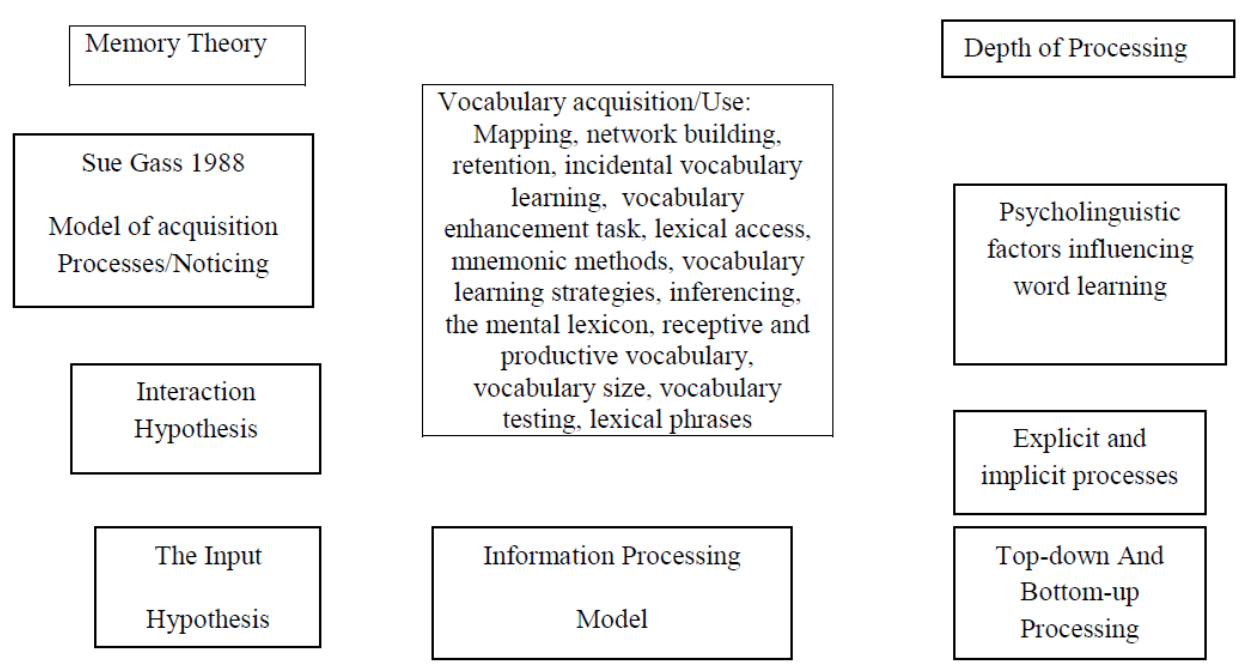

Figure 2. Examples of models and concepts from psycholinguistics and SLA theory (Haastrup and Henriksen, 2001)

In order to be more specific about three psycholinguistic stages of second language acquisition, (Levelt, 1989) suggests representation, acquisition, and processing. Consequently, introducing L1 model of vocabulary acquisition in relation to the L2 tailors our study to process and representation of vocabulary in the learner's mind and also the teacher's cognition.

Every lexical entry is made up of two components: the lemma and the lexeme. The lemma contains semantic and syntactic information about a word, e.g. word meaning and part of speech, and the lexeme contains morphological and formal information, e.g. spelling, and pronunciation. (Levelt, 1989). Fig. 3, shows the above terms:

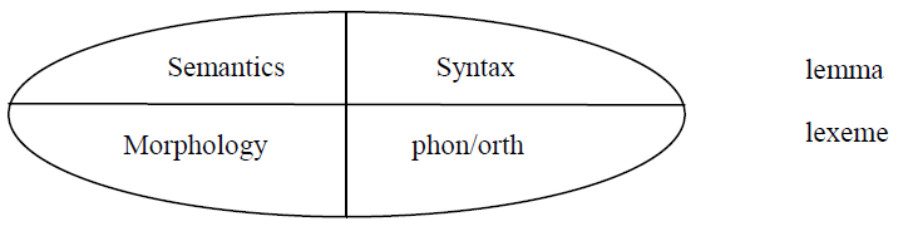

Figure3. The internal structure of a lexical entry (adapted from Levelt 1989)

Children acquiring their first language need highly contextualized input in order to extract semantic, syntactic, morphological, and phonological information. An alternative psycholinguistic model of vocabulary acquisition in L2 is more elaborated on in an article by (Jiang, 2000). She declares two distinguishing constraints on lexical development in L2 in instructional settings in comparison with L1. Fist, poverty of input in both quality and quantity in contextualized settings, secondly, the presence of an established conceptual/semantic system with an L1 lexical system closely associated with it. As a result, the learners in L2 settings pay more attention to formal aspects of the vocabulary e.g. spelling, pronunciation, and this stage lacks the lemma component of a lexical entry.

Accordingly, lexical development of a specific word evolves in the learning process through three stages: the first one is a formal stage, then as the learner's experience increments, the semantic and syntactic information by copying translation of an L1 happens, and finally, all the aspects of the lexical entry are established. Fig. 4, shows the pragmatic evolvement of the lexical entry:

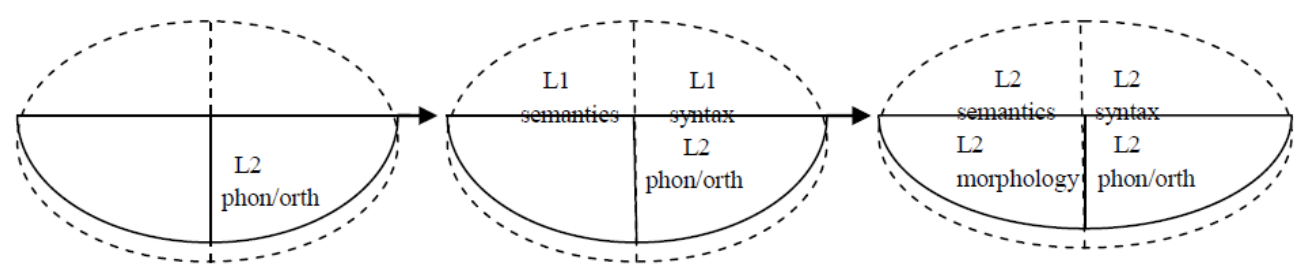

Figure 4. Lexical development in L2: from the formal stage to the integration stage (Jiang, 2000)

The psychologists and L2 vocabulary researchers believe that the more the learners are cautious about different aspects of a word, the higher the opportunities are that the new information will be retained. As a result, considering the above psycholinguistic models, if the individuals pay careful attention to the words' syntactical, semantic, morphological, pronunciation, and orthographical relations to other words, they are more likely to retain the word in the vocabulary learning during the word-focused activities (Hill and Laufer, 2003).

So far, we tried to explain the conditions of word formation and its representation both in L1 and L2.Therefore, these theories of psycholinguistic models can clarify our insight more powerfully toward teacher decision making and 
learners' processing during classroom practices about vocabulary learning and teaching. But, methods and procedures of vocabulary teaching should be discussed more.

Below, some vocabulary teaching exercises in the classroom will be presented, some of these exercises include:

- Text-based vocabulary exercises (Paribakt and Wesche, 1997),

- The vocabulary levels test (Nation, 1990),

- Vocabulary notebooks (Schmitt \& Schmitt, 1995),

- A multiple choice exercise and a gapped text (Hulstijn and Laufer, 2001),

- Consulting a dictionary, teacher's intervention, and using graphic devices e.g. pictures and different fonts and colors (Hill and Laufer, 2003).

Broadly speaking, each exercise needs its own strategy whether by the learner or the teacher's psychological interventions. Vocabulary learning strategies are classified into five strategies, as (Schmitt N. , 1997) cited in (Fowle, 2002): 'Social', involving interaction with others; 'Determination', deducing the meaning of a new word by one's self; 'Memory', relating new materials to existing knowledge; 'Cognitive', manipulation of knowledge by the learner; 'Metacognitive', involving decision making about the learning process.

\section{The present study}

This paper attempts to illustrate the other aspect of language teaching which always has been neglected. Since 1990, a host of research has been done in relation to language cognition and education, but few of them focused on teacher cognition in relation to vocabulary teaching. Because of the paramount importance which grammar takes (Borg, 1999), the other skills are de-emphasized. Accordingly, there is a huge gap in literature about the importance of vocabulary teaching, as a result, the necessity and importance of vocabulary teaching in relation to teacher cognition is investigated. Therefore, the purpose of this study is finding new ideas about vocabulary teaching which a particular teacher in a specified classroom thinks works best, and also the perspectives behind their instructional decisions in relation to the current issue.

Research questions

1) Is there a connection between teacher cognition and vocabulary teaching?

2) What are those areas of cognitions which teachers try to focus on more while teaching vocabularies?

\section{METHOD}

Every research tries to find the response to developing questions of that paper according to the need of the current issue. At the beginning of this paper the data elicitation was considered to be in form of a valid questionnaire. But after the pilot study there were a number of problems in relation to reliability and validity of the questionnaire. The questionnaire was adapted from (Richards, 1996), and then some appropriate modifications were done to adjust the instrument to our context.

The other problem was from participants. Although we considered four highly experienced and MA holders in TEFL, a page of introduction and explanations was given to them in advance. After the first distribution of questionnaires, lots of questions came into the mind of the participants that eventually the questionnaire was revised into an interview. As a result, the decision of data collection changed into a modified, one-hour semi-structured interview. Semi-structured interviews are generally based around a set of topics or a series of open-ended questions, they are flexible, they help the interviewee to be an active part of the interview, and they cause a conversation to proceed freely (Borg, 2006, p.203).

\section{A. Participants}

Due to the nature of the current study, teachers with too much expertise were an indispensable section of our research. As it is generally accepted, novice teachers with little expertise would be considered a fallacy (Kagan, 1992). The inexperienced teachers would generally focus on classroom management rather than new ideas to handle the existing issue related to teaching.

Consequently, four highly experienced teachers who earned their MA in TEFL were considered as the best options. In this respect, not only the focus of attention would be teacher cognition, but their education that is one of the variables will be scrutinized fully.

Each of these teachers had 10 years of experience of English teaching in educational system in Iran, and also they had one commonality, that is, teaching in the ILI, one of the well-known institutes in Iran.

\section{B. Procedure}

In order to get teachers to talk about their beliefs, thoughts, and mental constructs, verbal commentaries, one of the widely used strategies in the study of language teacher cognition, is applied (Borg, 2006). The research elicitation method is a semi-structured interview. Interview is specifically chosen in this study in the belief that they were more suited to capturing beliefs than questionnaires. This interview focused on the teacher cognition: 1) cognition and prior language learning experience 2) cognition and teacher education, and 3) cognition and classroom practice. The presentation of data in this paper is influenced by the belief that qualitative research is best conducted through the interpretation of data which the researcher finds best. The data are shown as four cases; illustrating the personal view of 
the interviewee and the thread of his mind while responding to the structured questions. Table 1 illustrates the list of questions used in the semi-structured interview:

TABLE 1.

SEMI-STRUCTURED INTERVIEW IN LANGUAGE TEACHER COGNITION

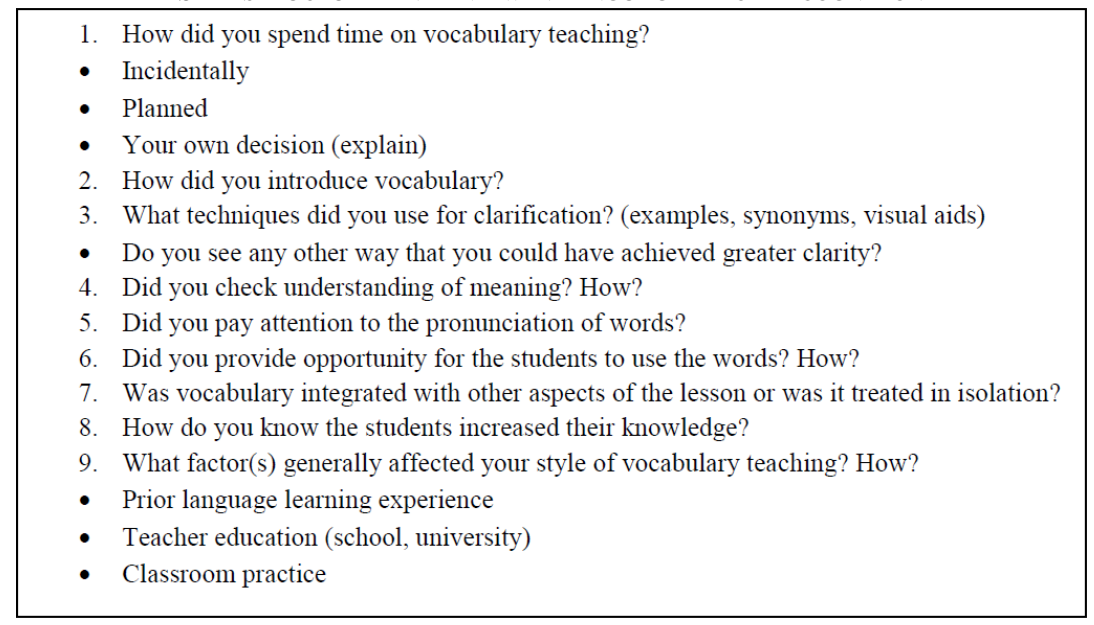

\section{RESULT}

\section{Case 1:}

Hamid was a 45-year-old male English teacher who had been teaching English for 18 years. He is an MA holder in TEFL from Azad University. His teaching was characterized by focusing on root explanation of what he called 'the experience of learning when he was an English student'.

In response to the first question, teaching vocabulary incidentally (as words came in) not according to a specified plan or objective, except the students didn't understand the meaning then he would go to his preferable approach, that is, root explanation.

In addition, he considered root teaching an interesting game not only for the students, but even for the teacher himself. For instance: to explain the word 'dictate', he would refer to the already known words such as 'dictionary', 'indicate', 'predict', and try to familiarize the students with the suffix "dict", and then he would elaborate on meaning in suffix, prefix, and find an example to contextualize the word for the students. Moreover, he believed that guessing the meaning through root explanation is such a fun game for learners that he would say 'when I look at them, I see their eyes glittering while I was talking about the roots'.

He didn't prefer eliciting the meaning of words during the presentation stage, except during the evaluation session.

The techniques which he used to clarify the meaning of the words include: giving examples, providing synonyms with similar suffixes and prefixes, and in relation to the level of the students and the difficulty of the words, he would resort to visual aids. Besides, he checked the understanding of meaning through current context, and even sometimes he would shift to mother tongue translation.

He also emphasized the pronunciation of the words, because he believed that words are tools of communication accordingly without correct pronunciation, negotiation of meaning would hinder.

He ascertained his idea of teaching that 'is there any other appropriate approach for teaching new vocabulary?'

The last question in relation to our issue was factors affected his style of vocabulary teaching?

For the past 18 years, I've been teaching at the ILI. Here, as you know, we have to stick to the methodology. However, affected by the teacher training courses we have had, But, at the higher levels, when I have to teach longer words, the way I do it I think is more affected by the approach and method I used to study at the university.

As a result, Hamid's vocabulary teaching was dominantly preoccupied by his educational background as a student, although the methodology and approach in the context he was using was fixed.

Case 2

Davud is a 36-year-old male English teacher who had been teaching English for 11 years. He is an MA holder in TEFL from Tabriz University. His favored technique was depending on his experience as a whole in relation to existing context of teaching. As a matter of fact he is so confident that he sees no necessity to rely on spoon feeding approaches.

As an introduction, he enjoyed the incidental learning and at times he follows his own approach. 'it depends on the level I am teaching, the students, the course objective, and the vocabulary itself'.

He would prefer more often introducing vocabulary from known to known because of the lesser cognitive load that may enhance learning that specified word. But he adds that depending on the difficulty of the word and the certain level, 
I may use different approaches. And in addition, this great sense of achievement of vocabulary learning is best received through educated guesses is really something.

In response to the question of the appropriate techniques for meaning clarification, he would prefer a variety of techniques according to the context of teaching: giving examples, providing synonyms, using context, visual aids, and even other techniques. Sometimes he would use 'weird comparison' with the native language as an interesting and practical device.

He believed on teaching vocabulary and pronunciation simultaneously, and considered it as an important part of language teaching:

The least is boosting the students' self-confidence through mastery of such subtleties, and I believe it is an integral part of language teaching.

Even he hoped for a change in his own approach if the last one was not practical. And he preferred indirect and different techniques for testing learners' comprehension.

And finally the last question about teacher cognition and the prior knowledge in which Davud stored as a repertoire to use in his teaching career will come as follow:

I won't ever forget the way I learned the joy of building my vocabulary through my teacher's detailed and versatile vocab-teaching. My teacher would spend a whole session on teaching anything directly or indirectly related to a single vocabulary item including shadowing of meaning, synonyms, antonyms, derivatives, homonyms, idioms, whatever you can imagine.

As a result, Davud' approach for vocabulary teaching is more dependent upon students' competency, level, and knowledge rather than the preplanned syllabus. And also he mentioned all the three variables (prior language experience, teacher education, and classroom practice) as important ones in forming his concept for vocab-teaching.

Case 3

Mohsen is a 30-year-old male English teacher who had been teaching English for 5 years. He is an MA holder in TEFL from Tarbiat Modares University. His main characteristic of teaching inspired from his prior knowledge as a university student, and classroom practice. Davud didn't believe in his cognition related to his teaching training courses.

From the beginning of the interview he frequently insisted on preparing himself before attending the classroom, so that he would check the pronunciation of every single word, planning each word according to its frequency and, etc.

Mohsen would like to initiate the lesson with already known words related to that session in order to link the semantic, syntactic, pronunciation, and spelling aspects of the previous words to the current words. And also he often relies on the students for guessing and doing the exercise by themselves.

Mohsen preferred all the mentioned strategies to clarify the meaning of the words. Not only he enjoyed using examples, synonyms, visual aids as tools for clarification, he also referred to glosses, and antonyms as helpful devices.

In response to the answer of meaning comprehension by the learners, he would say ' $I$ may ask them if they have understood the meaning well e.g. I ask them to make new sentences with the new words, and also from their facial expression everything is clear whether they got the meaning or not'.

Mohsen believed in checking pronunciation meanwhile teaching the words, he also checked his own pronunciation before attending the classroom. He would encourage the students to use the words in context, and voluntarily make sentences. In that way he may check the students' pronunciation and comprehension at the same time. He would integrate learning vocabulary with the reading and conversation in that lesson to make the meaning more plausible and meaningful.

Mohsen didn't prefer the fixed routine of procedure for teaching vocabulary; however, he would say that 'the way I teach is different from one class to the other, because the students, the context of teaching, actually everything is different from one class to the other.' And also he advised the students to read some supplementary materials e.g. magazine, extensively to make a deeper understanding from that particular session.

And finally, Mohsen believed in prior knowledge learning experience, and classroom practice as the most integral part of teacher cognition:

Certainly anybody knowing a second language has gathered a lot of experience during his/her own language experience. These experiences will actually affect his/ her teaching career.

\section{Case 4}

Mahdi is a 32-year-old male English teacher who had been teaching English for 8 years. He is a disciplined teacher, that is, he would like sticking to the methodology and preplanned syllabus.

Mahdi attempted to regard the planned syllabus before attending the classroom; therefore he taught the new words through finding a relationship with this lesson to the previous one.

For instance, to clarify the meaning of the word "talkative", I use a simple definition first, using some words they're familiar with:

**Talkative: A talkative person is one who likes to talk a lot!

As a second step, I'll give them a couple of examples using the new word in simple sentences:

**My friend is a talkative guy! He tells his whole life story to everyone he knows.

**I can't stand Rita! She's too talkative. 
However, in some cases, depending on the nature of the word I intend to clarify, I use real objects or visual aids like pictures.

Mahdi did believe in guessing the meaning of the words as one the useful strategies in assisting the learners to have greater effectiveness. 'I do agree! When they guess the meaning of a word from the context, a situation, or a picture, they tend to remember it for a longer period of time, maybe due to some psychological reasons (a sense of selfcenteredness, self-confidence, or accomplishment).'

He even emphasized the use of 'input flood' as a practical technique to increase students' vocabulary input through using them in sentences and giving them some examples.

For clarification of meaning he would prefer all the recommended strategies: giving examples, providing synonyms, and visual aids, except using the context. In terms of pronunciation, he would say that: 'Students get to pronounce a word the way they do it the first time! If they're exposed to wrong pronunciation the first time, they'll maintain it for a long time; in fact, it would be fossilized!'

Another interesting technique which Mahdi used in the class was the way he checked the students' understanding through 'selecting some related words and asking them to write a small paragraph using all those words'.

And finally, Mahdi elaborated on the last question meticulously; he unbelievably related his knowledge in English teaching to the teacher education courses which he had had during his university education, and also during the teacher training courses he had for attending as a teacher in the ILI.

In order to condense the preceding data into a comprehensible and straightforward notion, the following Table is illustrated:

TABLE 2.

\begin{tabular}{l|l|l|l|l} 
& \multicolumn{4}{|c}{ INFLUENCING COGNITIONS IN RELATION TO VOCABULARY TEACHING } \\
& Prior language experience & Teacher education & Classroom practice & Other \\
\hline Hamid & $\begin{array}{l}\text { Following the vocabulary } \\
\text { teaching, he had learnt } \\
\text { during his apprenticeship } \\
\text { in institution }\end{array}$ & $\begin{array}{l}\text { preoccupied by his } \\
\text { educational background }\end{array}$ & Limited \\
\hline Davud & Facilitate in his teaching & Practical in the classroom & undeveloped & $\begin{array}{l}\text { vocabulary teaching is } \\
\text { more dependent upon } \\
\text { students' competency, } \\
\text { level, and knowledge }\end{array}$ \\
\hline Mohsen & Integral & $\begin{array}{l}\text { Most integral aspect of } \\
\text { his cognition comprised } \\
\text { of his university and } \\
\text { teacher training courses }\end{array}$ & Planned syllabus & $?$ \\
\hline Mahdi & $?$ & input flood'
\end{tabular}

\section{DISCUSSION}

The data we have discussed here shows that teachers' decision about teaching vocabulary are fully affected through so many variables e.g. 'an interacting range of experiential, cognitive, and contextual factors' (Borg, 1999). The first variable, as elaborated by (Lortie, 1975), is called "apprenticeship of observation". It suggests that teachers' knowledge is fully influenced by their educational and professional experiences which are accumulated during their life span. The second one is somehow highly personalized; therefore the cognitive factor is individually different, because of the change of cognition in accordance with variable outcomes and individual developmental pathways (Badger \& White, 2001). And the last factor related to teachers' decision making is contextual factors or classroom practice which include: pedagogical consideration in the classroom and instructional maxims (Richards 1996).

Although each individual's response would be personalized to his own teaching and learning procedures, there were some stances which these teachers' ideas overlap in certain aspects. They all had consensus over clarifying the meaning of the words through giving examples, visual aids, and synonyms and, etc. All these commonalities and differences do not prove the justification of which cognitions are right and which are wrong! Teachers' cognitions have been evaluated according to several criteria:

- The clarity of reason teachers give for their instructional decisions

- The consistency of teachers' positions

- Teachers' ability to cite evidence

- Teachers' awareness of the factors which have led to development of these cognitions

- Teachers' willingness to consider alternatives to the grammar teaching practices and cognitions

These criteria help teachers analyze their teaching continuum, reflect on their practices, and clarify or modify the stages of teaching as acceptable or vague. Consequently, in the future the relationship of teaching and learning will be more reasonable, and teachers' decisions are more valid and plausible.

CONCLUSION AND IMPLICATIONS 
The essence of this discussion is that by studying L2 vocabulary teaching in relation to teacher cognition, a reasonable concept will be suggested about what the formal vocabulary teaching would be, and what the teachers do or know.

One stance here is provided by (Mitchell, Brumfit and Hooper, 1994) that according to study of English and foreign language teachers, those teachers' avoidance of technical vocabulary explanation...seemed linked to a lack of knowledge/insecurity in using grammatical or discourse terminology. Some support for this concept is provided by Mohsen and Mahdi's techniques in teaching vocabulary. They almost always for introducing the new words resort to the planned procedures. However, teachers who are more confident in their metalinguistic knowledge (such as Hamid) would never think of any preparation for pronunciation or other properties of new words.

According to psychological models of vocabulary teaching and learning (Haastrup and Henriksen, 2001), before teaching any word, all related psychological aspects of a single word should be taken into consideration (top-down and bottom-up processing, information processing, memory theory, input and interaction hypothesis and, etc). Therefore teacher's cognition would be in full correspondence with teaching that word, and the present condition of the learners in the classroom. For instance: Davud relied more on students' competency, level, and knowledge rather than the preplanned syllabus. He believed that teaching every certain vocabulary needs a direct attention to the students' ability to handle the situation, and afterwards he would go for the appropriate technique that suits those students and context.

As a result, we can plausibly come to conclusion that because of personalized nature of every teacher's cognition, all the variables related to cognition (prior knowledge and learning experience, teacher education, and classroom practice) would be invaluable according to the contextual factors. For instance: Hamid believed in the technique which he learned the vocabularies during his educational experience as a student. Davud agreed upon three variables as integral parts of his teaching career, he would shift to one of these variables in relation to the students' level and proficiency. Mohsen insisted on educational training which he received during his university study, and Mahdi would emphasize teaching training course he had had during pre-service teacher education.

This paper does not try prescribing any hard and fast rule about teaching and learning vocabulary. Besides it helps generate data about L2 teachers and teaching which may be useful in teacher education, in-service contexts. And also it would shed the light on teachers' problems in classroom, and enable the teachers to reflect on teaching techniques which are more practical.

A final issue which worth attention is the instructional context studied here confined to four non-native teachers, holding MA grades, teaching adults in Iran. This context may not be generalizable to the other contexts due to teachers' proficiency level, and long years of experience. The reason for selecting highly experienced and educated teachers would be gathering more reliable data to interpret, irrespective of any extraneous variables.

\section{REFERENCES}

[1] Bailey, K. M. (1996). The best laid plans: Teacher's in-class decisions to depart from their lesson plans. In K. M. Bailey \& D. Nunan (eds.), Voices from the language classroom. New York: Cambridge University Press, 15-40.

[2] Bailey, K.M., Bergthold, B., Braunstein, B., Jogodzinski Fleishman, N., Holbrook, M. P., Tuman, J., Waissbluth, X., \& Zambo, L. J. (1996). The language learners' autobiography: examining the "apprenticeship of observation'. In D. Freeman \& J. C. Richards (eds.), Teacher learning in language teaching. New York: Cambridge University Press, 11-29.

[3] Bartels, N. (1999). How teachers use their knowledge of English. In H.Trappes-Lomax \& I. McGarth (eds.), Theory in language teacher education. London: Prentice Hall, 46-56.

[4] Borg, S. (1997). Unifying concepts in the study of teacher's cognitive structures. Unpublished manuscript.

[5] Borg, S. (1999). Studying teacher cognition in second language grammar teaching. System 27.7, 19-31.

[6] Borg, S. (2003). Teacher cognition in language teaching: A review of research on what language teachres think, know, believe, and do. Language Teaching 36.4, 81-109.

[7] Borg, S. (2006). Teacher cognition and language education: Research and Practice. London: Continuum.

[8] Burns, A. (1996). Starting all over again: From teaching adults to teaching beginners. In D. Freeman and J. C. Richards (eds.), Teacher learning in language teaching. Cambridge: Cambridge University Press, 154-177.

[9] Coady, J., \& Huckin, T. (1997). Second language vocabuary acuisition. Cambridge: Cambridge University Press.

[10] Cumming, A. (1990). "Metalinguistic and ideational thinking in second language composing". Written communication 7.4, 482-511.

[11] Dornyei, Z. (2007). Research methods in applied linguistucs. Oxford: Oxford University Press.

[12] Farrel, T. L. C. (1999). The reflective assignment: Unlocking pre-service teachers' beliefs on grammar teaching. RELC Journal $30.2,1-17$

[13] Fowle, C. (2002). Vocabulary notebooks: Implementation and outcomes. ELT Journal 15.4, 380-388.

[14] Freeman, D. (1993). Remaining experience/reconstructing practice: Developing new understandings of teaching. Teaching and Teacher Education 9.5, 485-97.

[15] Golombek, P. R. (1998). A study of language teachers' personal practical knowledge. TESOL Quarterly 32.3, 447-64.

[16] Haastrup, K., \& Henriksen, B. (2001). The interrelationship between vocabulary acquisition theory and general SLA research. EUROSLA 12, 69-78.

[17] Harley, B. (1995). Lexical issues in language learning. Amesterdam: John Benjamins.

[18] Hill, M., \& Laufer, B. (2003). Type of task, time on task and electronic dictionaries incidental vocabulary acquisition. IRAL Journal 10, 87-106. 
[19] Hulstijn, J. H., \& Laufer, B. (2001). Some emprical evidence for the Involvment Load Hypothesis in vocabulary acquisition. Language Learning 51, 539-558.

[20] Jiang, N. (2000). Lexical representation and development in a second language. Applied Linguistics 14.4, 47-77.

[21] Johnson, E. (1994). The emerging beliefs and instructional practices of preservice English as a second language teachers. Teaching and Teacher Education 10.4, 439-52.

[22] Kagan, D. (1992). Proffetional growth among preservice and beginning teachers. Review of Educational Research 62,129-169.

[23] Levelt, W. (1989). Speaking: From intention to articulation. Cambridge, MA: Bradford.

[24] Lortie, D. (1975). Schoolteacher: A sociological study. Chicago: University of Chicago Press.

[25] Mitchell, R., Brumfit, C., \& Hooper, J. (1994). Knowledge about language: Policy, rationales, and practices. Research Papers in Education, 9(2), 183-205.

[26] Mitchell, R. A., \& Myles. (1998). Second language theories. London: Arnold.

[27] Nation, I. (1990). Testing and teaching vocabulary. New York: Heinle and Heinle.

[28] Paribakht, S., \& Wesche, M (ed.) (1999). Studies in second language acquisition: Special issues on incidental vocabulary acquisition. Current Research and Instructional Implications 21 .2, 223-245.

[29] Paribakt,T. S., \& Wesche, M. (1997). Vocabulary enhancement activities and reading for meaning in second language vocabulary development. In Reading-based exercises in second language vocabulary learning: An introspective study. New York: Cambridge University Press.

[30] Richards, J. C. (1996). Teachers' maxim in language teaching. TESOL Quarterly 30.2, 281-96.

[31] Richards, J. C., \& Pennington, M. (1998). The first year of teaching. In J. C. Richards (eds.), Beyond Training. Cambridge: Cambridge University Press, 173-190.

[32] Richards, J. C., Ho, B., \& Giblin, K. (1996). Learning how in the RSA Cert. In D. Freeman and J. C. Richards (eds.), Teacher Learning in Language Teaching. Cambridge: Cambridge University Press, 242-259.

[33] Schmitt, N. A., \& Schmitt. (1995). Vocabulary notebooks: Theoretical underpinnings and practical suggestions. ELT Journal 49, 133-143.

[34] Schmitt, N. (1997). 'Vocabulary learning strategies'.In N. Schmitt and M. McCarthy, Vocabulary: Description,acquisition, and pedagogy. Cambridge: Cambridge University Press.

[35] Schmitt, N., \& McCarthy, M. (1997). Vocabulary: Description, acquisition, and pedagogy. Cambridge: Cambridge University Press.

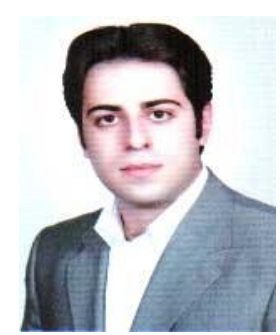

Siamak Rahimi was born in Kermanshah in 1983. He received his B.A in 2006 in English Literature in Razi University, Kermanshah, Iran. He earned his M.A in 2012 in TEFL in Shahid Beheshti University, Tehran, Iran.

$\mathrm{He}$ is an instructor in Islamic Azad University, Sureh University, and the ILI (Iran Language Institute). He is mainly interested in CDA, Testing, and Research studies.

Mr. Rahimi is also the directing manager in Tolu-e-Danesh Kish company. 